\title{
Editorial
}

\section{Elsevier's CiteScore index values for Acta Dermatovenerologica Alpina, Pannonica et Adriatica: a 2016 update}

\author{
Anja Šterbenc ${ }^{1,2 \bowtie}$, Anja Oštrbenk ${ }^{1}$
}

\begin{abstract}
Elsevier's recently launched citation metric CiteScore enables comprehensive, transparent, and current evaluation of a journal's performance. For an editorial office, insight into a journal's impact over time is of great value when making important decisions regarding the journal's future. A 2016 update of CiteScore index values for Acta Dermatovenerologica Alpina, Pannonica et Adriatica (Acta Dermatovenerol APA) showed a slight decrease in the CiteScore index value from 1.18 in 2015 to 0.96 in 2016. Acta Dermatovenerol APA can still be considered the principal journal in the field of dermatology and sexually transmitted infections in our region, with almost half of the articles published between 2013 and 2015 cited at least once in 2016. Acta Dermatovenerol APA performed well in both categories listed because it ranked 67th out of 121 journals in the category Dermatology (44th percentile) and $175^{\text {th }}$ out of 250 journals in the category Infectious Diseases (3oth percentile).
\end{abstract}

Received: 20 August 2017 | Returned for modification: 2 September 2017 | Accepted: 5 September 2017

In December 2016, the new citation metric CiteScore was launched by one of the world's major publishing companies, Elsevier. Using various metrics, CiteScore enables comprehensive, transparent, and current evaluation of a journal's impact, which can aid an editorial office in making crucial decisions regarding a journal's future (1).

The impact of Acta Dermatovenerologica Alpina, Pannonica et Adriatica (Acta Dermatovenerol APA) is closely monitored by our editorial office. The performance of our journal in 2015 was already presented in this year's first issue of Acta Dermatovenrol APA (2). Briefly, the CiteScore index value for our journal was 1.18 with 54\% of articles published between 2012 and 2014 cited at least once in 2015. Acta Dermatovenrol APA was listed in three categories; namely, General Medicine, Dermatology, and Infectious Diseases, where it ranked 384 th out of $1,549,53$ rd out of 122 , and 142nd out of 246 journals, respectively. Thus, the CiteScore index values for 2015 consolidated our journal's status as the leading journal in dermatology and sexually transmitted infections in our region.

In this editorial, we present Acta Dermatovenerol APA's most recent CiteScore index values (Table 1). In total, 67 articles that were published in Acta Dermatovenerol APA between 2013 and 2015 received 64 citations in 2016, resulting in a slightly lower Cit-
eScore index value for 2016 compared to 2015. Although a slight drop in the percentage of articles receiving at least one citation in 2016 was observed, nonetheless almost half of the articles published between 2013 and 2015 were cited at least once. In 2016, Acta Dermatovenerol APA was listed in the categories Dermatology and Infectious Diseases. The journal did well in both categories because it ranked 67th out of 121 journals in the category Dermatology (44th percentile) and 175th out of 250 journals in the category Infectious Diseases (3oth percentile).

Thus, Acta Dermatovenerol APA can still be considered the principal journal in the field of dermatology and sexually transmitted infections in this region. Nevertheless, our editorial office constantly strives toward further improvement of the journal's visibility and quality, which can primarily be achieved with the aid of our readers. In contrast to the official journal impact factor, CiteScore recognizes all articles as potentially citable, including editorials and letters to the editor, which are usually cited less often. Consequently, these articles artificially lower the journal's citation average (1). Because publishing in our journal is currently free of charge and our efforts are focused on increasing the number of high-quality articles, we strongly encourage our readers to submit their best original and review articles to Acta Dermatovenerol APA.

Table 1 | Acta Dermatovenerologica Alpina, Pannonica et Adriatica CiteScore index values for 2016.

\begin{tabular}{|c|c|c|c|c|c|c|}
\hline Category & CiteScore & CiteScore percentile & CiteScore rank & Citations 2016 & Documents 2013-2015 & $\%$ cited \\
\hline Dermatology & 0.96 & $44 \%$ & $67 / 121$ & 64 & 67 & $48 \%$ \\
\hline Infectious Diseases & 0.96 & $30 \%$ & $175 / 250$ & 64 & 67 & $48 \%$ \\
\hline
\end{tabular}

\section{References}

1. Van Noorden R. Controversial impact factor gets a heavyweight rival. Nature. 2016;540:325-6.

2. Poljak M. Coverage of Acta Dermatovenerologica Alpina, Pannonica et Adriatica in Elsevier's CiteScore index: a new tool for measuring the citation impact of academic journals. Acta Dermatovenerol Alp Pannonica Adriat. 2017;26:1-2. 